\title{
The Bacteriological study of chronic dacryocystitis
}

\author{
${ }^{1}$ Dr Shwetha B A, ${ }^{2}$ Dr Vittal Nayak I \\ ${ }^{1}$ Asst Prof, ${ }^{2}$ Prof and HOD \\ Dept Of Ophthalmology Vydehi Inst Of Medical Sciences And Research Centre Bangalore Karnataka,INDIA
}

\begin{abstract}
:
Purpose: To find out the bacteria involved in chronic dacryocystitis and their sensitivity to different antibiotics. Materials and methods: Study conducted on 200 patients. Inclusion criteria for the study are 1)Watering/mucopurulent discharge from eyes for more than 3 months.2)Preoperative evalution for cataract surgery revealing chronic dacryocystitis, excluding patients with block of nasolacrimal duct due to tumors and drugs. Discharge from puncta was collected with a moistened sterile swab without touching the lid margin or adjacent skin. In cases, without discharge, specimen was collected from the fluid regurgitating from puncta on lacrimal syringing. Material was sent for Gram's staining and culture plating on blood agar, Mc Conkey's agar. Examination of the plates was done after 18-24 hours. If no growth is seen, plates are further incubated for 48 hours. Sensitivity to antibiotics was tested by Kirky Bauer method or Muller-Hinton agar method.

Results: Out of 200 patients, 115 showed a positive bacterial growth, of which 74\% were gram-positive and $34 \%$ were gram-negative organisms, 85 did not show any growth. Staphylococcus aureus 37, Klebsiella 17, Pneumococci 13, mixed cultures7, Staphylococcus epidermidis 10, alpha hemolytic streptococci 5, B. catarrhalis 5 and anaerobes 3.

The antibiotic sensitivity patterns are as below, Staphylococcus aureus sensitive to Ciprofloxacin, Klebsiella sensitive to Gentamicin, Ciprofloxacin, Norfloxacin and Cotrimoxazole, Pneumococci sensitive to Amoxycillin, Penicillin, E.coli sensitive to Gentamicin, Ciprofloxacin and Norfloxacin and B. catarrhalis sensitive to Amoxycillin, Penicillin, Ciprofloxacin, Norfloxacin and Doxycycline.

Conclusions: The present study revealed that most commonly encountered organism was Staphylococcus aureus which is most sensitive to Ciprofloxacin.

Key Words: Chronic dacryocystitis, Bacteriological study, Lacrimal apparatus, Gram's stain, culture plating on blood agar, Mc Conkey's agar, Kirky Bauer method and Muller Hinton method.
\end{abstract}

\section{Introduction:}

Dacryocystitis - inflammation of the lacrimal sac and duct - is a common and unpleasant disease, partly because of the troublesome and conspicuous tearing it may cause, partly because it has little tendency to resolve and its adequate treatment presents considerable problems.

The peculiar location of the lacrimal sac i.e., at the junction of the orbit and nose makes it to be frequently involved by diseases of both these sites and in turn it can lead to complications in either of the adjoining structures.

Dacryocystitis is a problem not only to the patients but also to the ophthalmologist. It not only causes social embarrassment by constant watering and discharge but also a menace to the integrity of the eye. It is usually caused due to an obstruction to flow of tears in the bony passages, that leads to stasis in the sac, which gets infected. Organisms from both ends of the passage can infect the sac and also infection in paranasal sinuses, oral cavity and anywhere else in the body can spread to the sac. Hence a detailed examination to rule out any infected foci is a must.

Dacryocystitis in turn can spread to involve other adjoining structures due to continuity and by haematogenous route to involve distant sites. It causes chronic conjunctivitis, bacterial persistent ulcers, panophthalmitis with loss of the eyeball, facial cellulitis, orbital cellulitis and even cavernous sinus thrombosis can occur, putting the patient's life in danger. Dacryocystitis could be, congenital, acquired or traumatic.

Untreated dacryocystitis never undergoes spontaneous resolution. Any decisions as to the lines of treatment should be preceded by a complete investigation of the lacrimal passages without which cases will inevitably occur wherein the wrong treatment is adopted.

In view of the above facts, this bacteriological study was undertaken keeping in mind the following aims:

1. To find out the bacteria involved in chronic dacryocystitis and their sensitivity to different antibiotics.

2. To estimate the frequency of commonly occurring organisms in this part of the country.

3. To compare incidence of chronic dacryocystitis in both the sexes. 
In this way the best line of treatment can be decided for the patient.

\section{Materials And Methods :}

A prospective study was undertaken to find out the bacteria involved in chronic dacryocystitis and their sensitivity to different antibiotics.

It included 200 patients attending the OPD at Vydehi Institute of Medical Sciences and Research Center. The study was conducted from June 2005 to June 2007. the patients who satisfied the following criteria were included in the study.

- Watering or mucopurulent discharge from the eyes for more than 3 months

- Preoperative investigations for cataract surgery revealing chronic dacryocystitis.

Patients with block of nasolacrimal duct due to tumors and drugs were excluded.

A detailed history including age, socioeconomic status, type of complaint and duration of complaints, treatment take elsewhere was noted followed by temperature, blood pressure, pulse recording and systemic examination.

A thorough ocular examination to look for regurgitation from the puncta on pressure over these area, swelling, any other abnormalities and lacrimal syringing was carried out, followed by examination of the nose.

Purulent material from the puncta was collected with a moistened sterile swab without touching the lid margin or adjacent skin. In cases, without discharge, the specimen was collected from the fluid regurgitating from the puncta on lacrimal syringing.

The material was sent for Gram's staining and culture plating on blood agar and Mc Conkey's agar. Examination of the plates was done after 18-24 hours. If no growth is seen, the plates are further incubated for 48 hours.

Scrapings from corneal ulcers were taken from the edges and the base with a moistened sterile swab and directly plated. Sensitivity to antibiotics like Ciprofloxacin, Norfloxacin, Gentamycin, amoxycillin, penicillin, Doxycycline and Cotrimoxazole was tested by the disc diffusion technique or Kirky Bauer method or Muller-Hinton agar.

In all patient investigations like urine sugar $\mathrm{Hb} \%, \mathrm{TC}, \mathrm{BT}$ and $\mathrm{CT}$ were carried out.

\section{Results}

Table 1

Age Incidence

\begin{tabular}{|c|c|c|}
\hline Age Group in years & No. of patients & \\
\hline $30-39$ & 59 & 30 \\
\hline $40-49$ & 71 & 36 \\
\hline $50-59$ & 35 & 18 \\
\hline $60-69$ & 16 & 8 \\
\hline $70-79$ & 19 & 10 \\
\hline
\end{tabular}

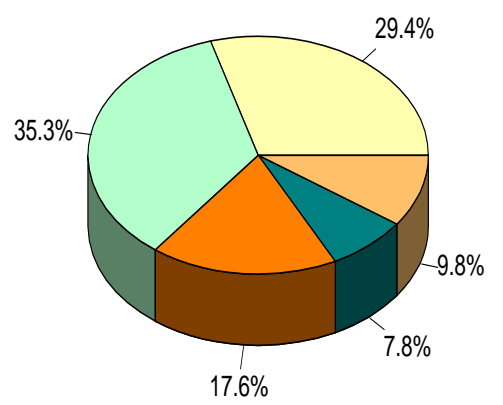

$\square$ 30-39 $\square$ 40-49 $\square 50-59 \square 60-69 \square 70-79$

The maximum number of cases was seen in the age group of 40-49 yrs followed by 30-39 years and 50-59 year.

Table 2

Sex Incidence

\begin{tabular}{|l|c|c|}
\hline Group & No. of patients & Percentage \\
\hline Male & 72 & $36 \%$ \\
\hline Female & 128 & $64 \%$ \\
\hline
\end{tabular}




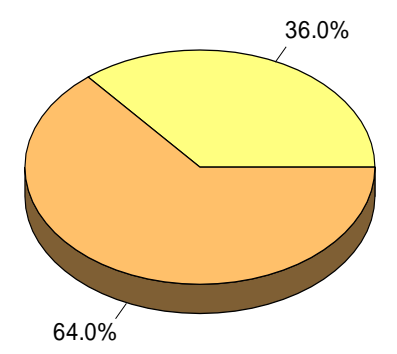

$\square$ Male $\square$ Female

The incidence in females (64\%) was much higher than in males (36\%)

Table 3

Laterality

\begin{tabular}{|l|c|c|}
\hline Side & No. of patients & Percentage \\
\hline Right & 120 & 60 \\
\hline Left & 50 & 25 \\
\hline Bilateral & 30 & 15 \\
\hline
\end{tabular}

Table 3 Laterality Side No. of patients Percentage Right 12060 Left 5025 Bilateral 3015

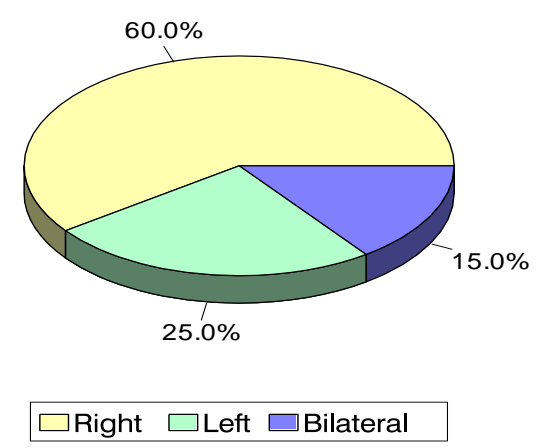

The percentage of patients with involvement of the right side (6.0\%) was much higher, followed by involvement of the left side $(25 \%)$ and bilateral involvement (15\%).

\section{Table 4}

Presenting features

\begin{tabular}{|l|c|c|}
\hline & No. of patients & Percentage \\
\hline Epiphora & 168 & 84 \\
\hline Mucopurulent discharge & 82 & 41 \\
\hline Diminution of vision & 24 & 12 \\
\hline Conjunctivitis & 28 & 14 \\
\hline Fistula & 8 & 4 \\
\hline
\end{tabular}

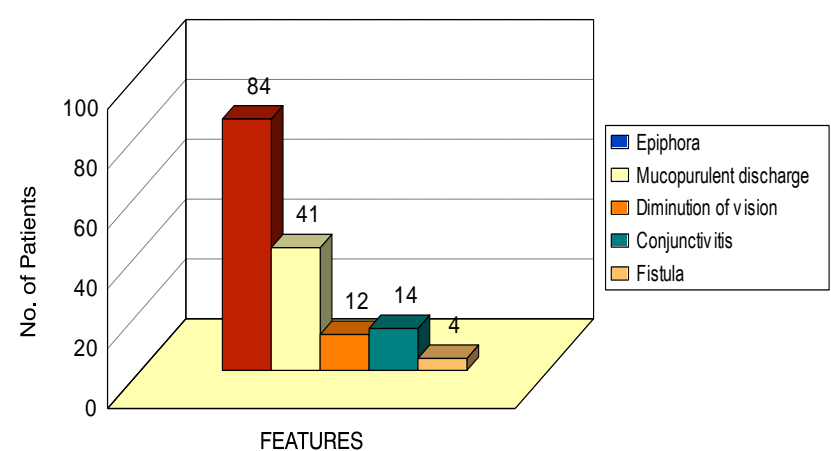

$84 \%$ of the patients presented with epiphora $41 \%$ of the patients had mucopurulent discharge followed by conjunctivitis (14\%) diminution of vision (12\%) and fistula (4\%) 
Table 5

Bacteriological features

\begin{tabular}{|l|c|c|}
\hline & No. of patients & Percentage \\
\hline Positive bacterial growth & 115 & 57.5 \\
\hline Sterile & 85 & 42.5 \\
\hline
\end{tabular}

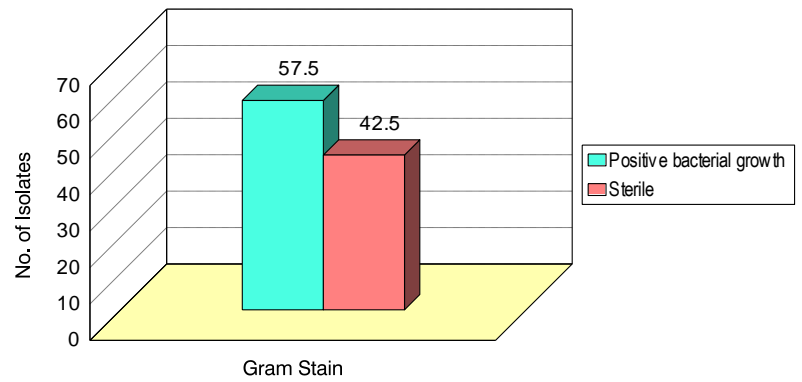

$57.5 \%$ of the patients showed a positive bacterial growth while $42.5 \%$ of patients had no growth

Table 6

Gram Staining Pattern

\begin{tabular}{|l|c|c|}
\hline Gram Stain & No. of Isolates & Percentage \\
\hline Gram-positive & 85 & $68.55 \%$ \\
\hline Gram-negative & 39 & $31.45 \%$ \\
\hline
\end{tabular}

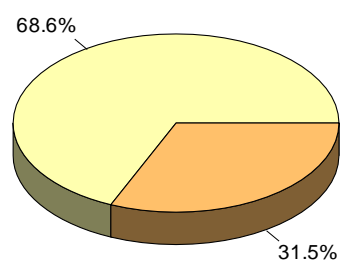

$\square$ Gram Positive $\square$ Gram Negative

$68.55 \%(84 / 124)$ of the isolates were gram-positive and $31.45 \%(39 / 124)$ were gram-negative

Table 7

Bacterial pattern

\begin{tabular}{|l|c|c|}
\hline Type of bacteria & No. of isolates & Percentage \\
\hline Staphylococcus aureus & 37 & 32.17 \\
\hline Klebsiella & 17 & 14.78 \\
\hline Pneumococci & 13 & 11.30 \\
\hline Staphylococcus epidermidis & 10 & 8.69 \\
\hline Diphtheroids & 4 & 3.47 \\
\hline Streptococcus fecalis & 6 & 5.21 \\
\hline Pseudomonas & 8 & 6.95 \\
\hline Alpha hemolytic streptococci & 5 & 4.34 \\
\hline Branhamella catarrhalis & 5 & 4.34 \\
\hline Anaerobes & 3 & 2.6 \\
\hline Mixed-cultures & 7 & 6.08 \\
\hline
\end{tabular}

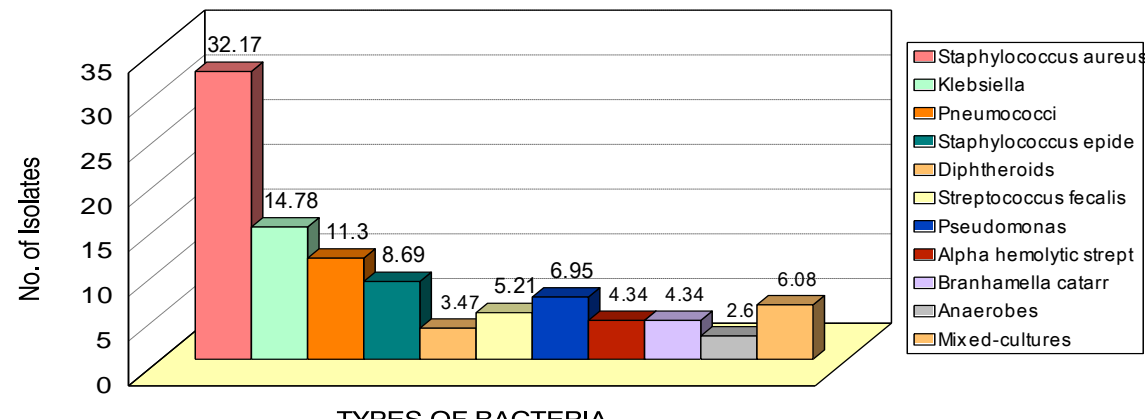

TYPES OF BACTERIA 
Out of the 115 isolates Staphylococcus aureus was isolated in $32.17 \%$ (37/115) of patients, Klebsiella in $14.78 \%$ (17/115), Pneumococci in $11.30 \%$ (13/115), Staph epidermidis in $8.69 \%$ (10/115), Diphtheroids in $3.47 \%$ (4/115), Strep fecalis in 5.21\% (4/115), Pseudomonas in 6.95\% (8/115), Alpha hemolytic streptococci in $4.34 \%$ (5/115), Branhamella catarrhalis in 4.34\% (5/115), Anaerobes in 2.6\% (3/115) and mixed cultures in $6.08 \%(7 / 115)$. Anaerobes were identified indirectly by their Gram-positively and sterile cultures on aerobic media. Mixed cultures included E. Coli and Klebsiella in 2 patients and Staph aureus and Klebsiella in 5 patients.

\section{Table 8}

\section{Antibiogram (Sensitivity Percentage)}

\begin{tabular}{|l|c|c|}
\hline \multicolumn{1}{|c|}{ Antibiotic } & No. of isolates sensitive to & Sensitivity percentage \\
\hline Amoxycillin & 54 & 46.95 \\
\hline Penicillin & 38 & 33.04 \\
\hline Gentamicin & 77 & 66.95 \\
\hline Ciprofloxacin & 99 & 86.08 \\
\hline Norfloxacin & 73 & 63.47 \\
\hline Cotrimoxazole & 54 & 46.95 \\
\hline Doxycycline & 38 & 33.04 \\
\hline
\end{tabular}

The present study showed 46.95\% (54/115) sensitivity to Amoxycillin, 33.04(38/115) sensitivity to Penicillin, $66.95 \%$ (77/115) sensitivity to Gentamicin $86.08 \%$ (99/115) sensitivity to Ciprofloxacin, 63.47\% (73/115) sensitivity to Norfloxacin, $46.95 \%$ (54/115) sensitivity to Cotrimoxazole and $33.04 \%(38 / 115)$ sensitivity to Doxycycline.

Table 9

Sensitivity pattern of the isolates

\begin{tabular}{|l|c|c|c|c|c|c|c|}
\hline Organisms & Amoxycillin & Penicillin & Gentamycin & Ciprofloxacin & Norfloxacin & Cotrimoxazole & Doxycycline \\
\hline Staph aureus & 36.36 & 18.18 & 63.63 & 72.72 & 45.45 & - & 18.18 \\
\hline Klebsiella & 57.14 & - & 100 & 100 & 100 & 100 & 57.14 \\
\hline Pneumococci & 100 & 100 & - & 100 & - & 100 & 33.33 \\
\hline $\begin{array}{l}\text { Staph } \\
\text { epidermidis }\end{array}$ & 100 & 100 & 100 & 100 & 100 & - & - \\
\hline $\begin{array}{l}\text { Alpha } \\
\text { hemolytic } \\
\text { strep }\end{array}$ & 100 & 100 & - & 100 & - & 100 & 100 \\
\hline Pseudomonas & - & - & 100 & 100 & 100 & 100 & 100 \\
\hline Strep fecalis & - & - & 100 & - & - & - & - \\
\hline E.coli & - & - & 100 & 100 & 100 & 100 & - \\
\hline
\end{tabular}

According to this table staph aureus was most (72.72\%) sensitive to Ciprofloxacin, Klebsiella was $100 \%$ sensitive to Gentamicin, ciprofloxacin, Norfloxacin and Cotrimoxazole, Pneumococci was $100 \%$ sensitive to Amoxycillin, Penicillin, Ciprofloxacin and Cotrimoxazole, Staph epidemidis was $100 \%$ sensitive to Amoxycillin, Penicillin, Ciprofloxacin and Norfloxacin, Alpha hemolytic strep was 100\% sensitive to Amoxycillin, Penicillin, Ciprofloxacin, Cotrimoxazole and Doxycycline, Strep fecalis was $100 \%$ sensitive to Gentamicin and Cotrimoxazole, E.coli was $100 \%$ sensitive to Gentamicin, Ciprofloxacin, Norfloxacin and Cotrimoxazole, Diphtheroids were 100\% sensitive to Ciprofloxacin and Norfloxacin and B. catarrhalis was $100 \%$ sensitive to Amoxycillin, Penicillin, Ciprofloxacin, Norfloxacin and Doxycycline

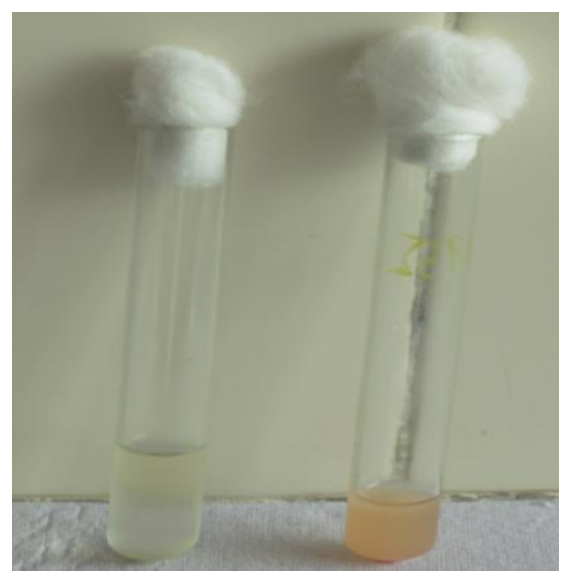

Fig. 1: Tube Coagulase Test - Positive and Negative: 


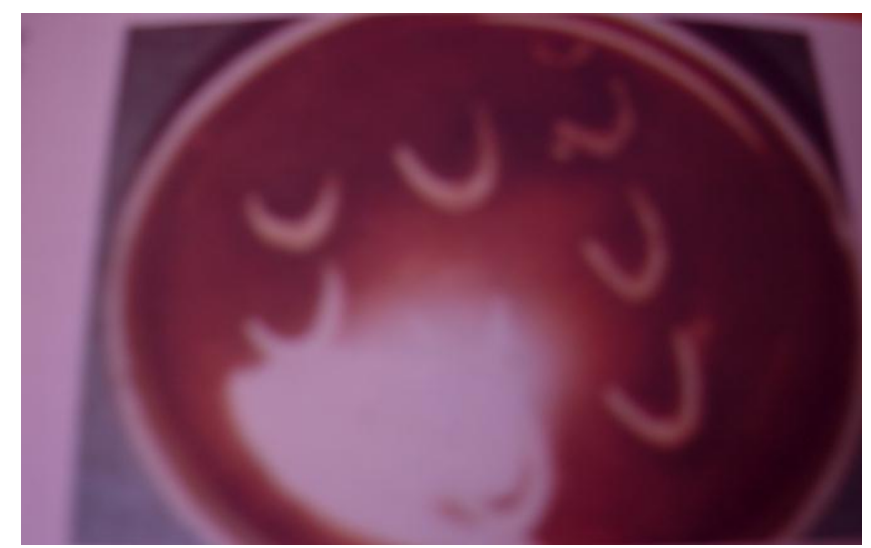

Fig. 2: C-streak inoculation of blood agar showing Staphylococcal colonies

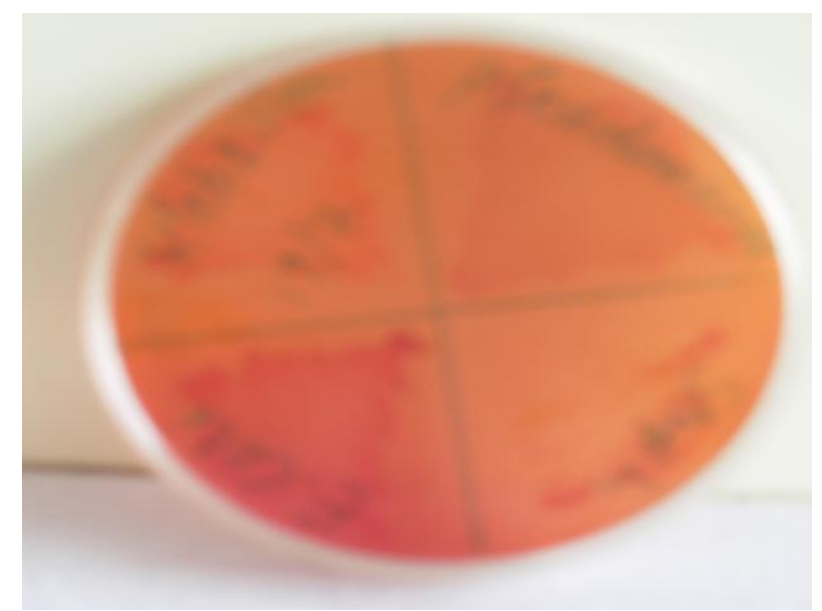

Fig. 3: Culture plate

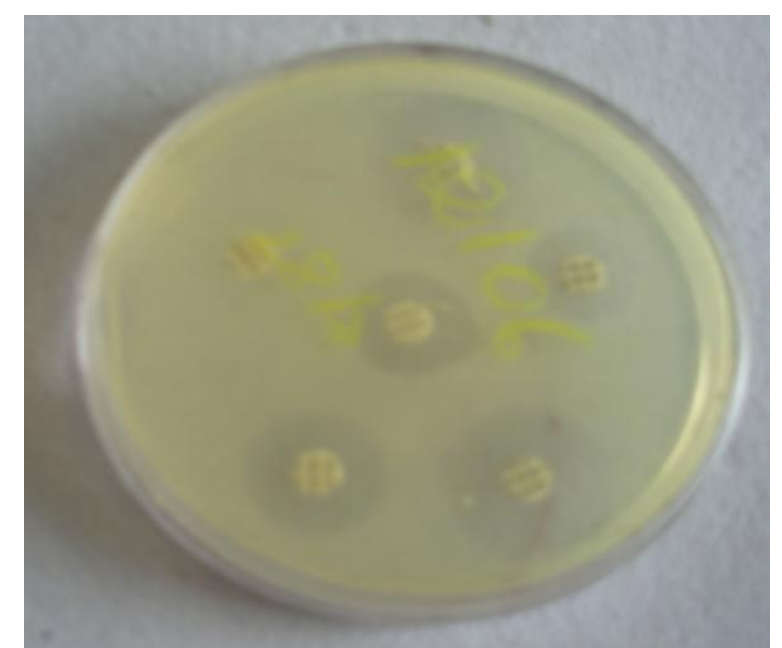

Fig. 4 : Antibiotic sensitivity testing on Muller Hinton Agar

\section{Discussion :}

This prospective study of 200 patients was done to determine the type of bacteria involved in patients with chronic dacryocystitis.

In the present study the most common organism isolated was Staph aureus 32\% followed by Klebsiella $14 \%$ and Pneumococci 11\%. Among the mixed cultures also Klebsiella and Staph aureus predominated. Mixed cultures were seen in $6 \%$ of cases ( 2 patient was positive for E.coli and Klebsiella and 5 patients were positive for Staph aureus and Klebsiella). 
The present study showed 46.95\% (54/115) sensitivity to Amoxycillin, 33.04\% (38/115) sensitivity to Penicillin, 66.95\% (77/115) sensitivity to Gentamicin, $86.08 \%$ (99/115) sensitivity to Ciprofloxacin, $63.47 \%$ (73/115) sensitivity to Norfloxacin, $46.95 \%$ (54/115) sensitivity to Cotrimoxazole and $33.04 \%$ (38/115) sensitivity to Doxycycline.

This study showed that staph aureus was most $(72.72 \%)$ sensitive to Ciprofloxacin, Klebsiella was $100 \%$ sensitive to Gentamicin, Ciprofloxacin, Norfloxacin and Cotrimoxazole, Pneumococci was 100\% sensitive to Amoxycillin, Penicillin, Ciprofloxacin and Cotrimoxazole, Staph epidemidis was $100 \%$ sensitive to Amoxycillin, Penicillin, Ciprofloxacin and Norfloxacin, Alpha hemolytic strep was $100 \%$ sensitive to Amoxycillin, Penicillin, Ciprofloxacin, Cotrimoxazole and Doxycycline, Strep fecalis was $100 \%$ sensitive to Gentamicin and Cotrimoxazole, E.coli was 100\% sensitive to Gentamicin, Ciprofloxacin, Norfloxacin and Cotrimoxazole, Diphtheroids were $100 \%$ sensitive to Ciprofloxacin and Norfloxacin and B. Catarrhalis was 100\% sensitive to Amoxycillin, Penicillin, Ciprofloxacin, Norfloxacin and Doxycycline.

\section{References :}

[1] Hurwitz JJ. Embryology of the lacrimal drainage system. In: Hurwitz JJ (ed) The lacrimal system. Philadelphia, Lippincott Raven, 1996.

[2] Langman J. Medical Embryology, Ch. 17 Baltimore: Williams \& Wilkins, 1963

[3] Duke-Elder S, Cook C. Embryology, In: Duke -Elder S (eds) Systems of Ophthalmology, Vol III, Part I. London: Henry Kimpton, 1963.

[4] Sevel D. Development and congenital abnormalities of the nasolacrimal apparatus. J Pediat Ophthalmol Strabismus 1981; 18: 1319.

[5] Jones LT. An anatomical approach to problems of the eyelids and lacrimal apparatus. Arch Ophthalmol 1961; 66: 111.

[6] Maurice DM. The dynamics of drainage of tears. In: The Preocular Tear Film and Dry Eye Syndromes Boston: Little, Brown 1973.

[7] Jones LT. The lacrimal secretory system and its treatment. Am J Ophthalmol 1966; 62: 47-64.

[8] Jones LT, Wobig JL. Surgery of the eyelids and lacrimal system. Birmingham: Aesculapius; 1976.

[9] Doane MG Blinking \& the mechanics of the lacrimal drainage system. Ophthalmol 1981; 88: 844.

[10] Duke-Elder S, Mac Faul P. The ocular adnexa. In : System of Ophthalmology St. Louis CV Mosby, 1974; pp 724-759.

[11] Jones LT. Tear sac foreign bodies. Am J Ophthalmol 1965; 60: 111.

[12] Dr. P. Chitrarajalakshmi, Dr. Lalitha P. In: Ocular Microbiology Dept of Ocular Microbiology and Pathology - Aravind Eye Hospital; pp3.

[13] Anderson DR. Unilateral epiphora caused by a papilloma of the lower canaliculus. Arch Ophthalmol 1967; 78: 618

[14] Adenis JP, Mattion C, Lebrand P and Franco Limoges JL. DCR: Indications, Technique, Results - A retrospective study of 165 cases. J Fr Ophthalmol 1987; 10: 323:329.

[15] Karesh JW, Perman KI, Rodrigues MM (Sinai Hosp of Baltimore, MD; Univ of Maryland, Baltimore; Washington Hosp Ctr, Washington, DC). Dacryocystitis associated with malignant lymphoma of the lacrimal sac. Ophthalmology 1993; 100: 669-673.

[16] Baron EM, Kersten RC, Kulwin DR (Univ of Cincinnati, Ohio) Rhabdomyoma manifesting as acquired nasolacrimal duct obstruction Am J Ophthalmol 1993; 115: 239-242.

[17] Punita K. Sand Ravinder K. Curvulaia dacryostitis A report of 2 cases. Orbit 2000; 19 (1): 45-56.

[18] Bouzas A. Canalicular inflammation in ophthalmic cases of herpes zoster and simplex. Am J Ophthalmol 1965; 60: 713.

[19] Brook I, Frazier EH. Aerobic and anaerobic microbiology of dacryocystitis. Am J Ophthalmol 1998 Apr; 125(4): 552-4.

[20] Artenstein AW, Eiseman AS, Campbell GC. Chronic dacryocystitis caused by Mycobacterium Fortuitum. Ophthalmology 1993 May; 100(5): 666-8.

[21] De Angelis D, Hurwitz J, Mazzulli T. The role of bacteriologic infection in the etiology of nasolacrimal duct obstruction. Can J Ophthalmol 2001 Apr; 3693: 134-9.

[22] Blicker JA, Buffam FV. Lacrimal sac, conjunctival and nasal culture results in dacryocystorhinostomy patients. Ophthal Plast Reconstr Surg 1993; 9(1): 43-6.

[23] Siva Reddy et al - Dacryocystitis - A clinicopathological study. J. Ind Med Assoc 1955; 24: 413-416.

[24] Sood NN et al. Chronic dacryocystitis: A clinico-bacteriological study. J Am Indian Ophthal 1967; 15: 107-110.

[25] Rajeev N.B. Dacryocystitis Bacteriological study and its relationship with nasal pathology I J O 1987; Vol. 55, No. 4 178-187.

[26] Kuchar A, Lukas J, Steinkogler FJ Bacteriology and antibiotic therapy in congenital nasolacrimal duct obstruction. Acta Ophthalmol Scand 2000 Dec; 78(6): 694-8.

[27] Phillips MG, Young JD. Value of bacterial culturing in the course of congenital nasolacrimal duct obstruction J. Pediatr Ophthalmol Strabismus 1994 Jul-Aug; 31(4): 246-50.

[28] Mac Ewen CJ, Phillips MG, Young JDH (Ninewells Hosp \& Med School, Dundee, Scotland) Value of bacterial culturing in the course of congenital nasolacrimal duct obstruction J Pediatr Ophthalmol Strabismus 1994; 31: 246-250.

[29] Milder B, Demorest BH. Dacryocystography, I The normal lacrimal apparatus, Arch Ophthalmol 1954; 51: 180.Russell EJ, Czervionke L, Hunckman M, et al. CT of the inferomedial orbit and the lacrimal drainage apparatus: Normal \& pathologic anatomy AJR 1985; 145: 1147- 1154. 